f

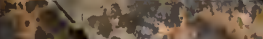

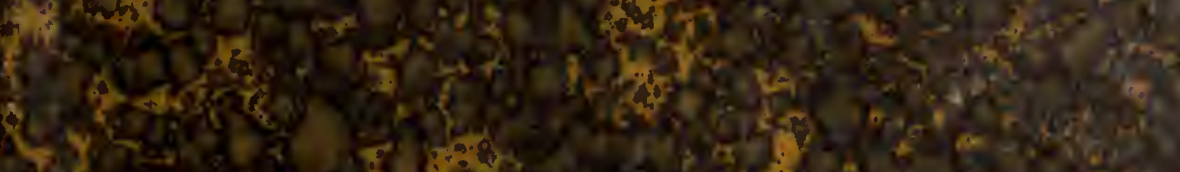

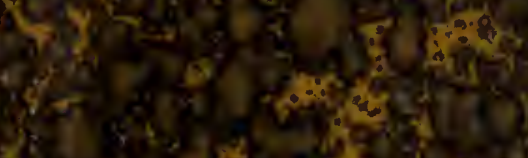
$3 \cos ^{2}: \frac{1}{4}$

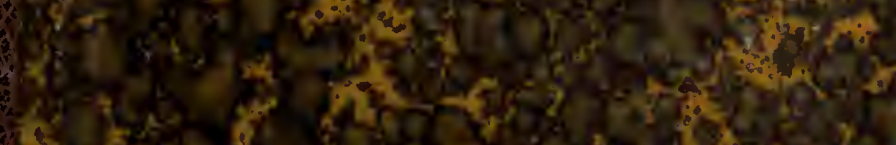
on

1.t1 101,

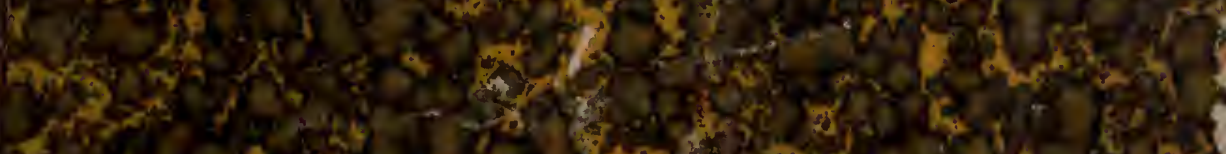

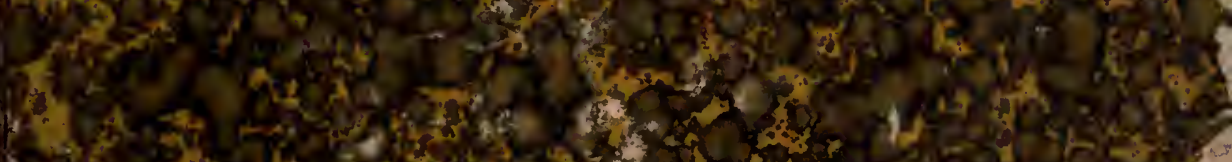
2.

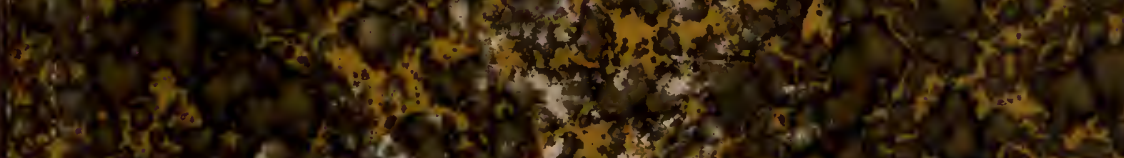

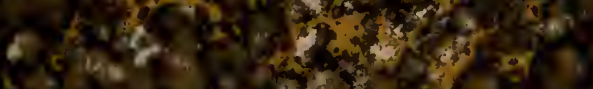
6ris

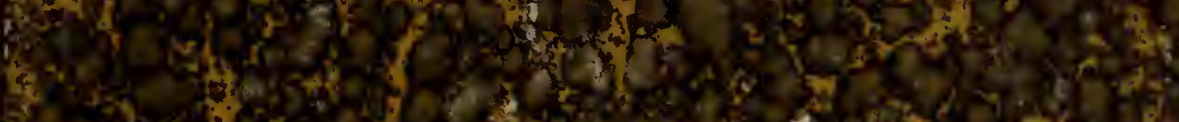

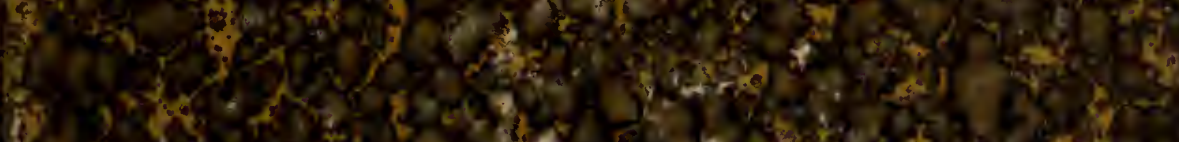
32 s

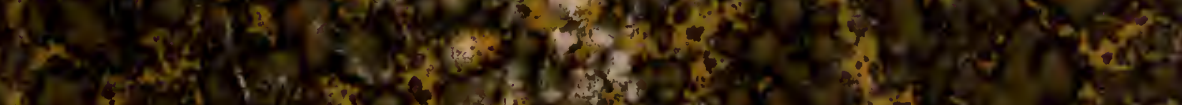

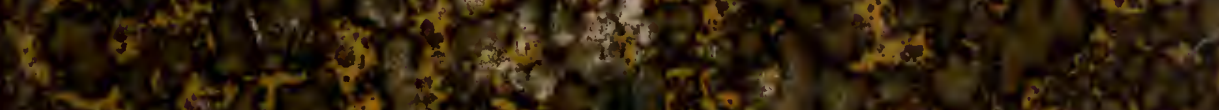

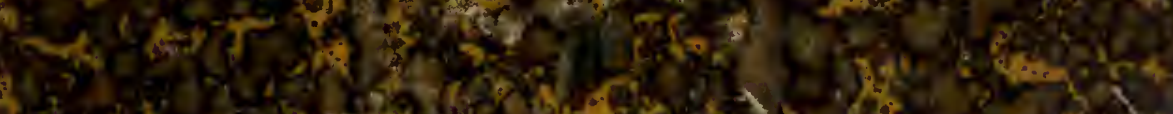

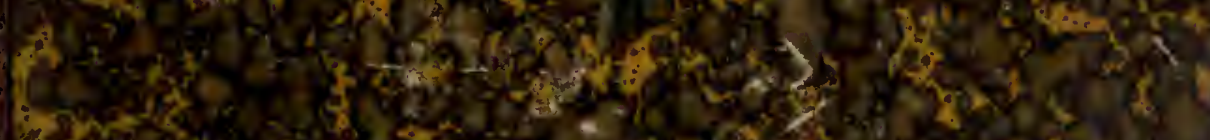

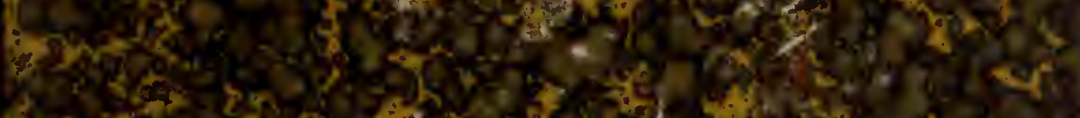

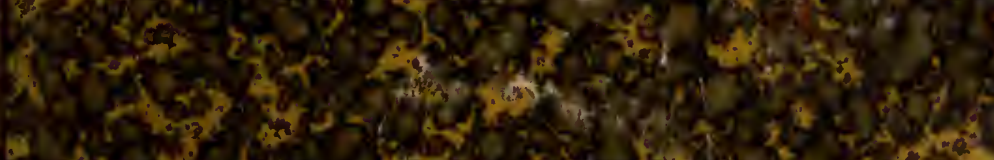

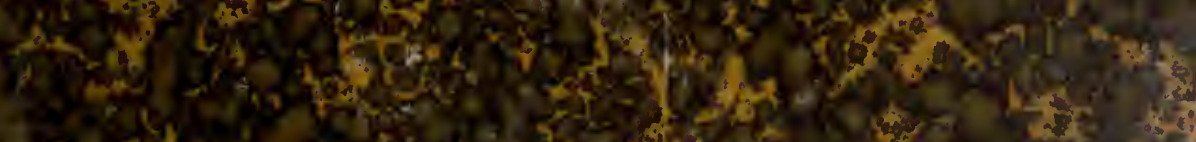
9.

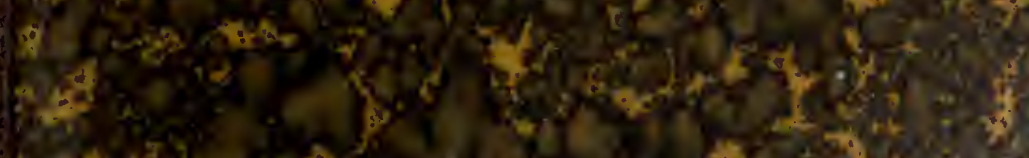

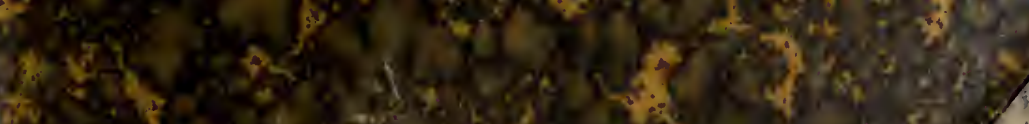

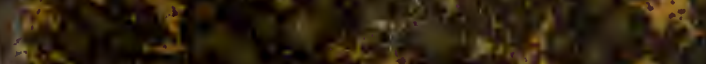




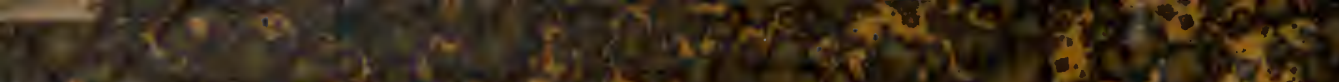

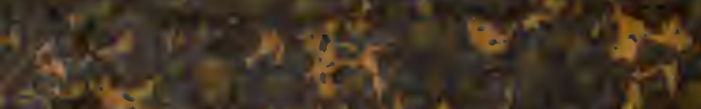

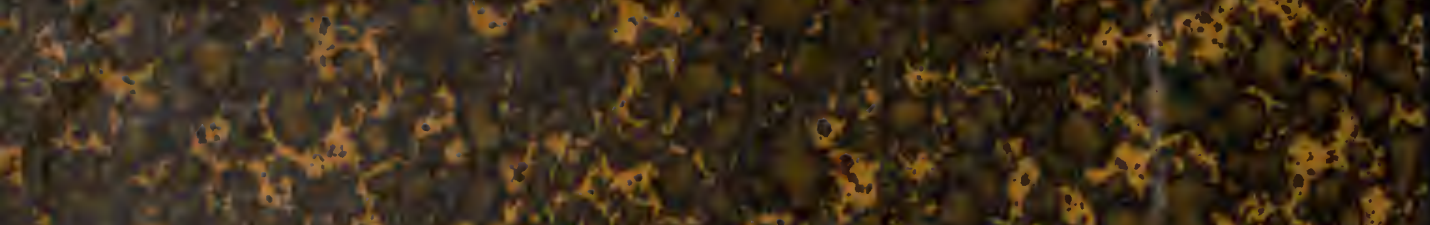
4.

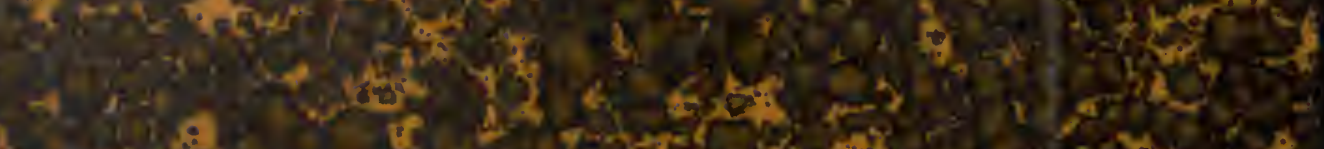

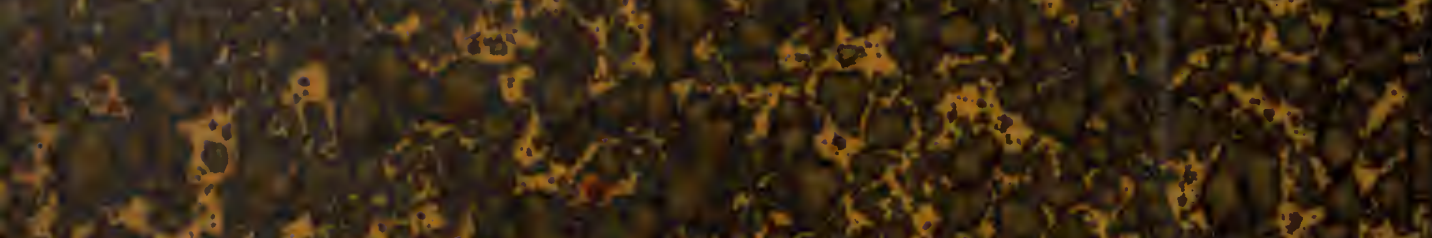

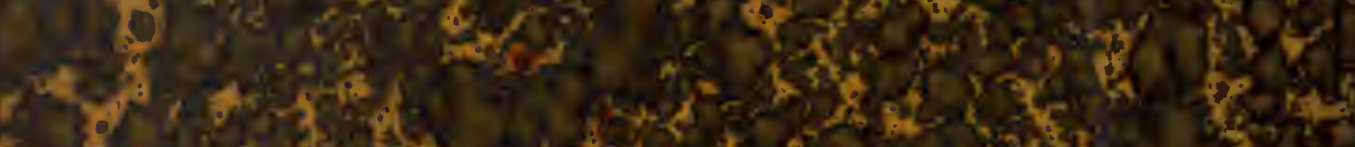

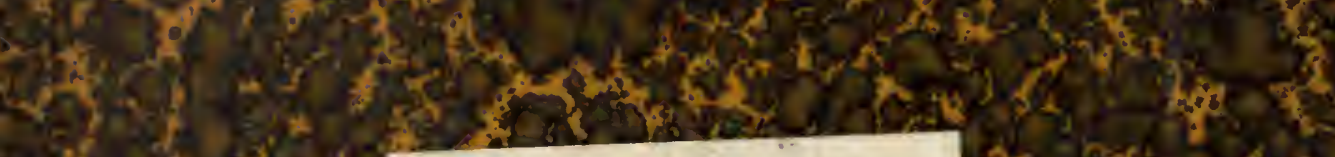

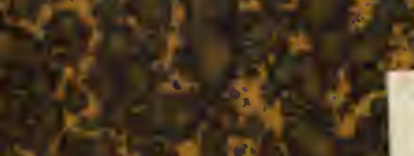
A. The The THE UNIVERSITY

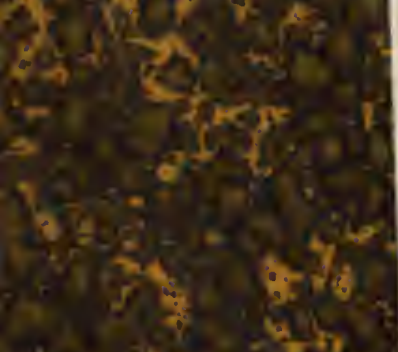

3.

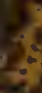

$x_{3} x^{2}$

OF ILLINOIS

LIBRARY

Bis of 30

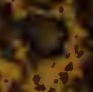
$\cos (x-2)=74$

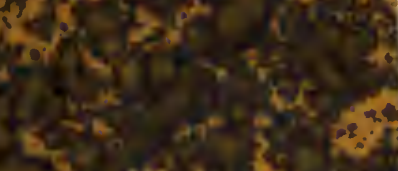

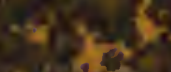

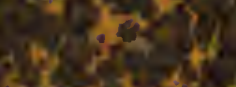

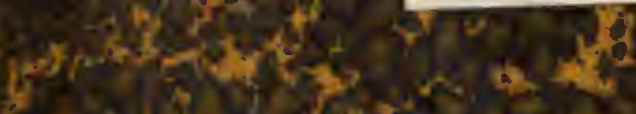

590.5 F.T

afparmatis

BIOLOGI

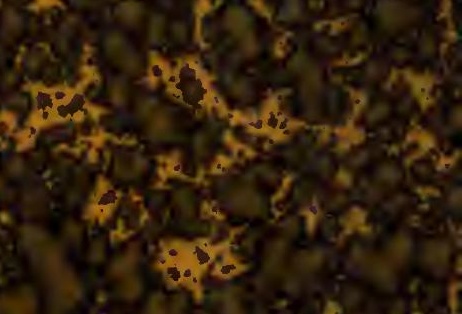

A.t.

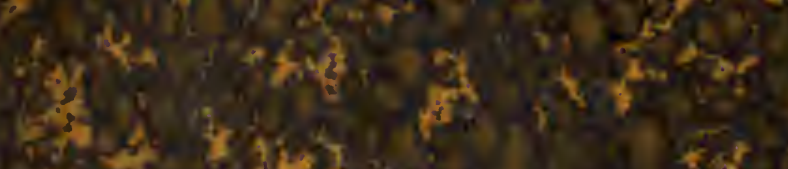

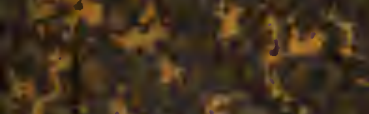

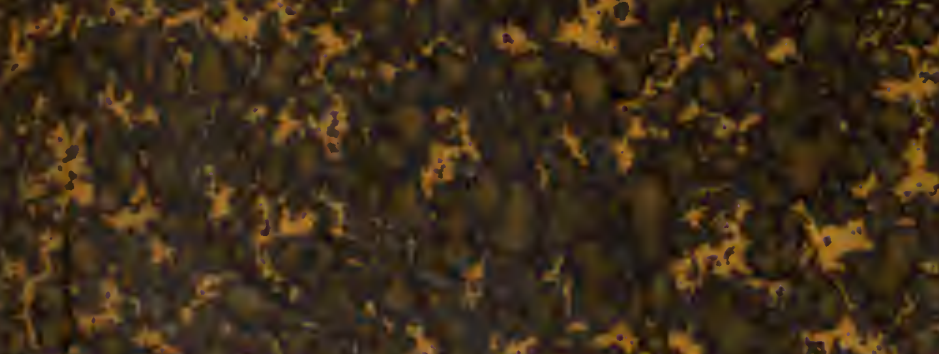







\title{
Field Columbian Museum
}

\section{Publication i i 6.}

Zoölogical Series.

Vol. VII, No. 3 .

\section{DESCRIPTION OF THREE NEW SPECIES OF FISHES FROM MIDDLE AMERICA}

\author{
BY \\ Seth Eugene Meek, \\ Assistant Curator of Department.
}

Charles B. Cory, Curator of Department.

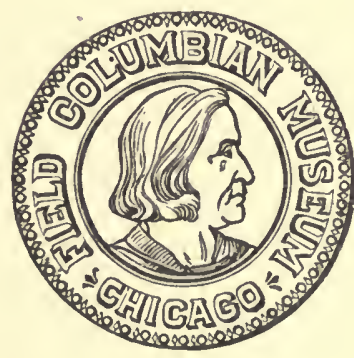

Chicago, U. S. A. July, i 906. 



\section{DESCRIPTION OF THREE NEW SPECIES OF FISHES FROM MIDDLE AMERICA.}

\section{BY SETH EUGENE MEEK.}

In a collection of fishes recently made by me in Guatemala, I find several specimens of Cichlasoma trimaculatum (Gthr.). Comparing these with the specimens from Achotal, Mexico, which I listed as belonging to this species, I find the latter to be a different species and one undescribed. In the following paper it and two new species of fishes from Guatemala are described.

\section{Family Siluridae.}

Rhamdia cabrerae sp. nov.

Type No. 5500, Amatitlan, Guatemala. Total length, I $36 \mathrm{~mm}$.

Head, 4.6I; depth, 5.30; D. I, 7; A. II. Body elongate, robust, compressed posteriorly; head somewhat depressed; narrowed forward; upper jaw the longer; maxillary barbels reaching to or slightly past base of pectorals; -outer mandibidular barbels barely reaching gill openings; eye small, 5 in head, slightly before middle of the head; snout 2.70 in head; interorbital 2.75; head covered with soft skin; fontanelle extending to base of occipital process; the bridge at posterior margin of orbits; occipital process very short; humeral process small, not reaching beyond third of pectoral spine; pectoral spine strong not pungent, its inner margin serrate, its length 2.40 in head; dorsal spine weak; height of dorsal fin $\mathrm{I} .40$ in head, its length $\mathrm{I} .95$; last dorsal ray slightly in advance of base of ventrals; base of pectoral to base of ventral 3.60 in body; snout to base of dorsal 3.20 in body; adipose fin $3.5^{\circ}$ in body; base of anal r. 50 in head; caudal fin short, the lower lobe the larger; least depth of caudal peduncle r.6o in head.

Color, dark brownish, ventral region silvery, no lateral band, fins dark, no distinct band on middle of dorsal.

This fish apparently does not grow large. The largest seen by me was $\mathrm{r} 60 \mathrm{~mm}$. in length. Collected by S. E. Meek.

Named for Señor Don Manuel Estrada Cabrera, President of the Republic of Guatemala, whose interest in the study of the fishes of Lake Amatitlan led to its discovery. 


\section{Family Cichlidae.}

Cichlasoma centrale sp. nov.

Type No. 5510, Caballo Blanco, Guatemala. Total length, Iо3 $\mathrm{mm}$.

Head 2.6I; depth 2.34; D. XVI, II; A. VII, 8; scales 6-32-II. Body elongate, rather robust, the dorsal region not much elevated, the profile nearly a straight line; mouth rather large, the lower jaw the longer; the two anterior teeth of upper jaw much larger than the others; anterior pair of teeth of lower jaw small, the next pair on each side canine-like; maxillary reaching vertical from anterior margin of orbit, its length 3 in head; preorbital 5.76; postorbital 2.25; diameter of eye 3.66 ; mandible 2.14 ; lower lip without frenum; cheeks with 6 rows of scales; longest dorsal spine 2.72 in head; longest anal spine 2.50; least depth of caudal peduncle 2.54 ; pectoral fin scarcely reaching first anal spine, its length 1.45 in head; tips of ventral reaching to base of first anal spine, length 1.48 ; tips of ventrals and middle dorsal rays not produced; caudal fin rounded.

Color, dark olivaceous; sides with 7 faint vertical bars; a black spot on middle of each of last four bars. A black ocellated spot on upper half of base of caudal fin; no dark lateral band; a black spot on shoulder just above anterior end of lateral line ; a few faint brownish spots on base of soft dorsal and anal.

This species bears some resemblance to Cichlasoma trimaculatum (Gthr.). It is more slender, has lower dorsal and anal fins, and shorter ventrals. The tips of the ventrals in a specimen of $C$. trimaculatum (Gthr.) $97 \mathrm{~mm}$. in length reach to base of 4 th anal spine. Collected by S. E. Meek.

Cichlasoma tenue sp. nov.

Type No. 378I, Achotal, Vera Cruz, Mexico. Total length $95 \mathrm{~mm}$. Head 2.48 ; depth 2.45 ; D. XVI or XVII, 9 or Io; A. VI or VI, 7. Body elongate not robust, dorsal region not elevated, the profile nearly straight, mouth rather large, the lower jaw the longer; the anterior pair of teeth of upper jaw enlarged; the anterior pair of lower jaw small, the next pair on each side canine-like; lips thick, the lower without frenum; maxillary reaching vertical from anterior margin of eye, its length 2.95 in head; preorbital 6.ro; postorbital 2.20 ; eye 3.45 ; mandible 2.14 ; cheeks with 5 rows of scales; longest dorsal spine 2.65; longest anal spine 2.50; least depth of caudal 2.65; pectoral fin reaching first anal spine, length $\mathrm{r} .46$ in head; tips 
of ventrals reaching base of $4^{\text {th }}$ anal spine, $\mathrm{r} .35$ in head; tips of ventrals and dorsal and anal fins produced in filaments; caudal fin rounded.

Color, light olivaceous, sides with 7 obscure dark bars; a black humeral spot, a more or less ocellated spot on upper half of base of caudal; a faint dark blotch usually on middle of last 4 bars, the one on 4 th bar prominent; no spots on vertical fin.

In a former paper* I identified these specimens as Cichlasoma trimaculatum (Gthr.). Since then I have obtained specimens of that species from Caballo Blanco, Guatemala, and find it a much deeper fish than the one here described. In the Museum are six specimens of this species ranging in length from $47 \mathrm{~mm}$. to . I04 $\mathrm{mm}$. Collected by Heller and Barber.

* Proc. Biol. Soc. Wash., r905, 245. 






\section{4

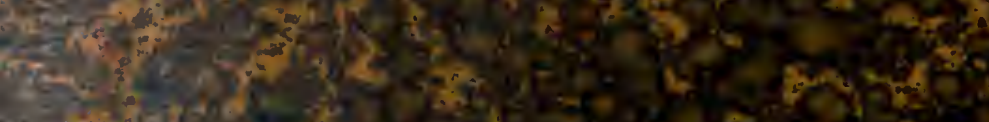

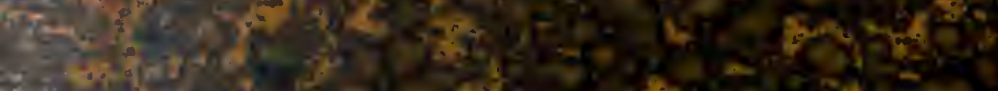

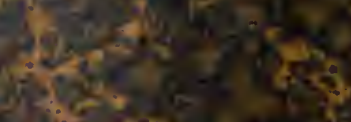

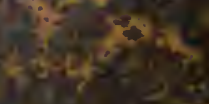

(6)

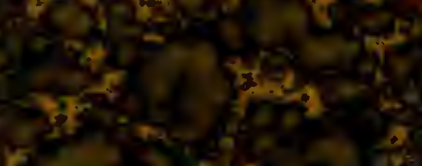

5.

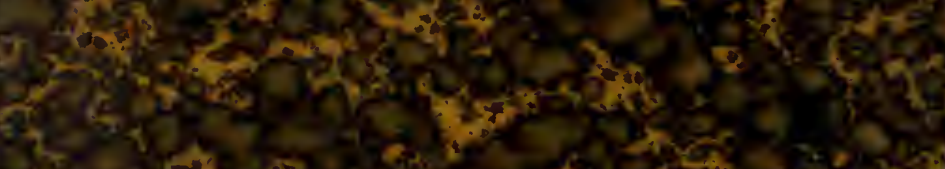

B. 40 . (5) 3.

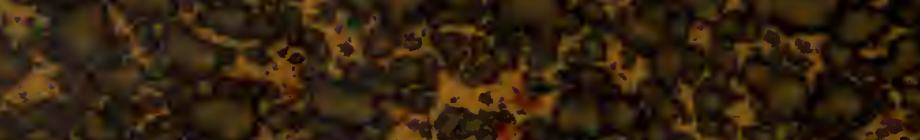
a

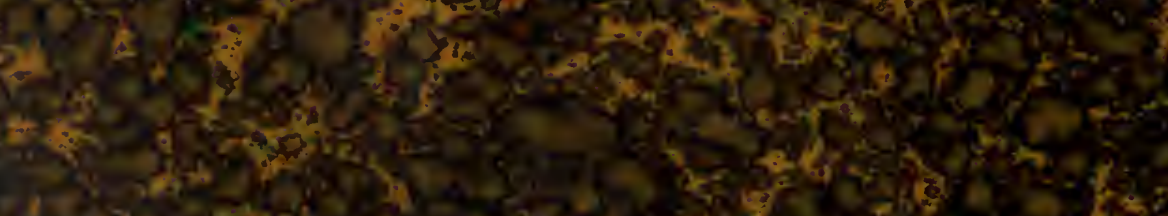
35 in

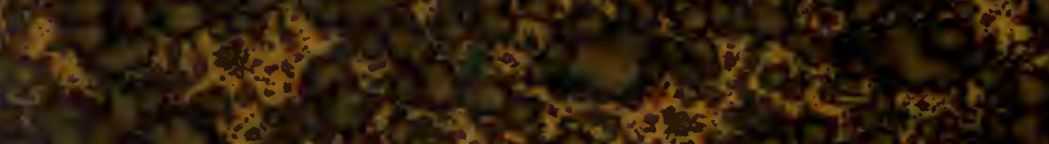
50

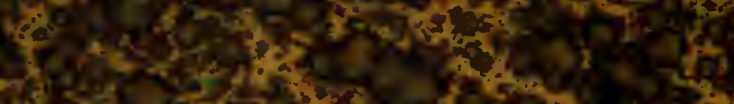
Ne (5)

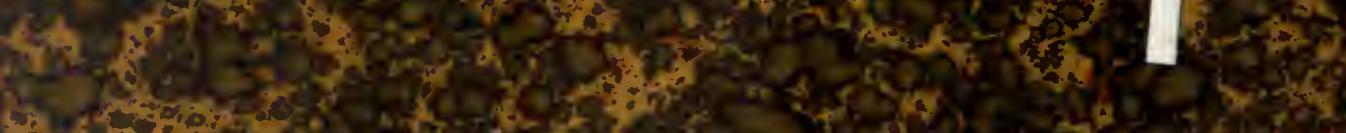
S.

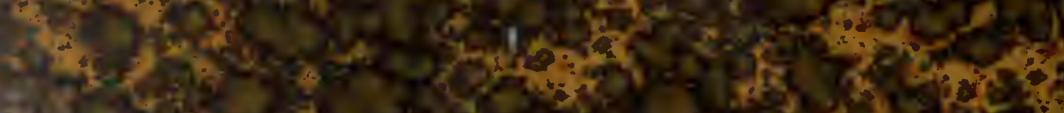

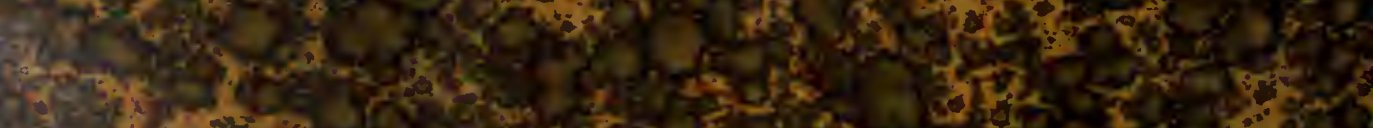

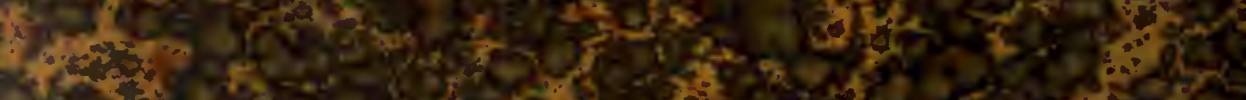

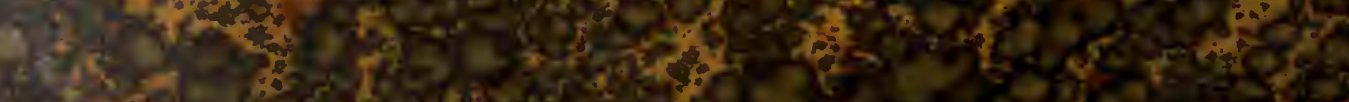




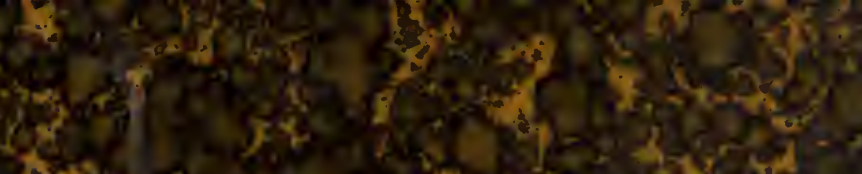

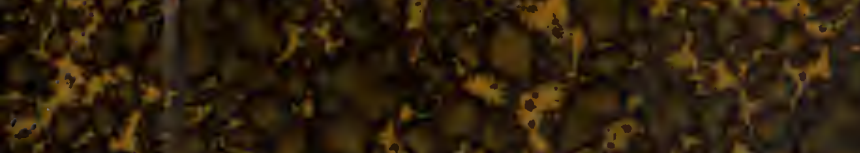

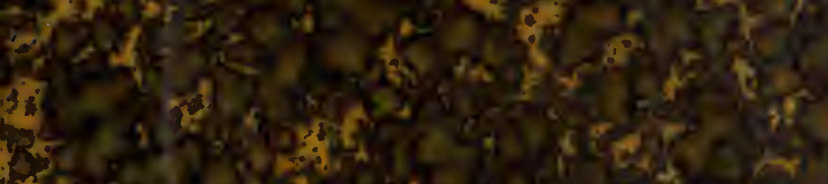

2.) $3 \times 189$ 10 8 5 . 5 ( $4 x^{2}$ 40 3

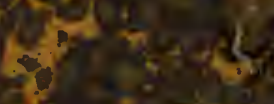

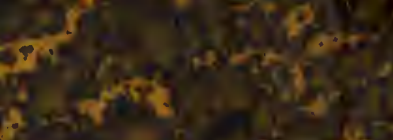
is

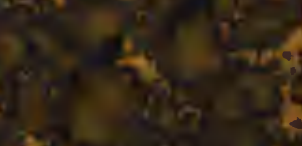
$\lim _{4} \frac{1}{2}$ tis. +

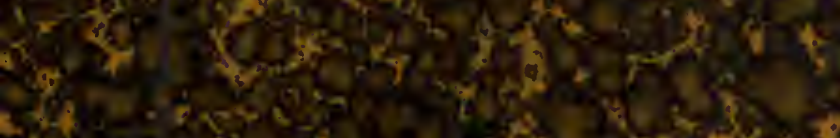

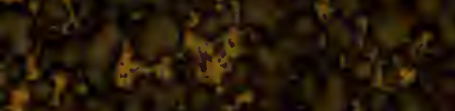

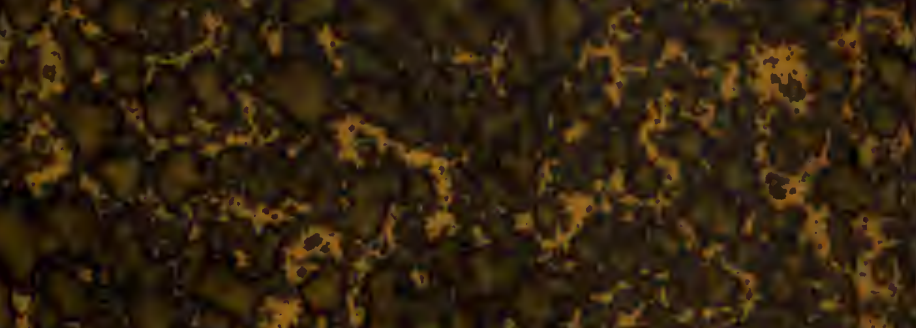

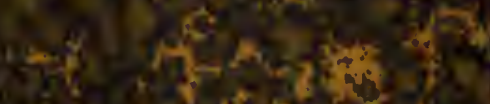
its $\frac{1}{2}$

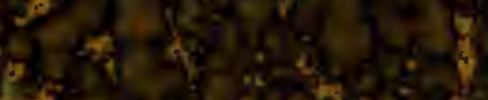

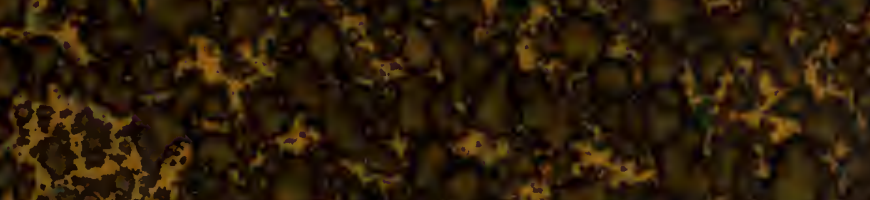
$x^{2}+4$ सin?

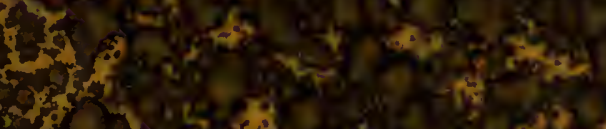

\section{510} Yo 5 A N IIS 40 의 1 50 1 50 1 50 4. $\rightarrow x^{2}$ in. 2303

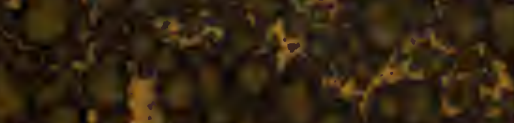
8

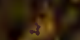
6 Wontom

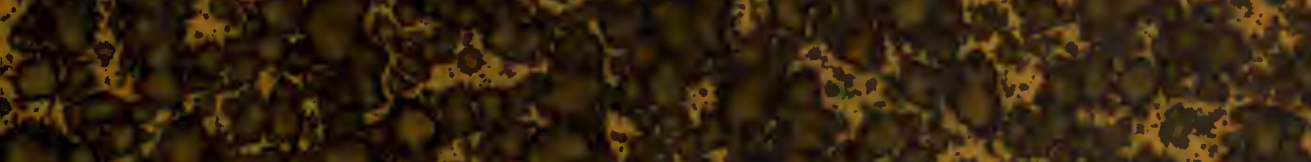
(6)

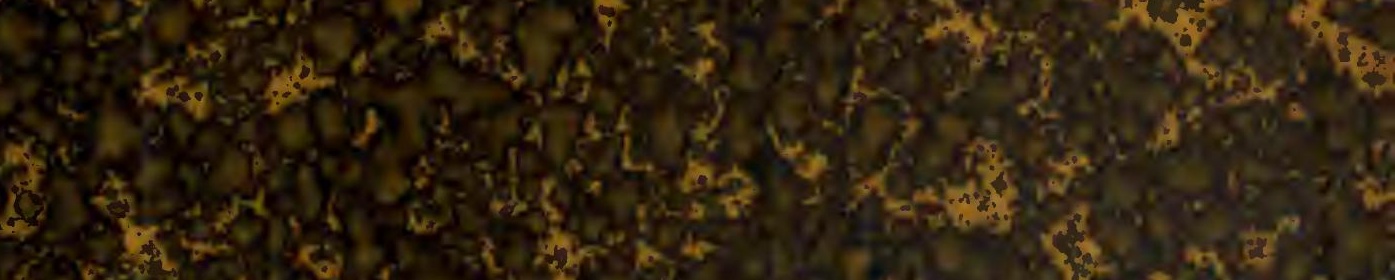

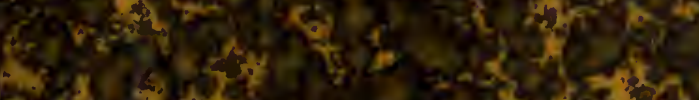

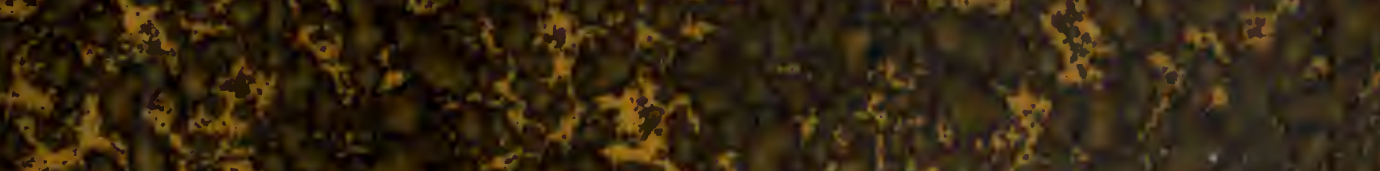

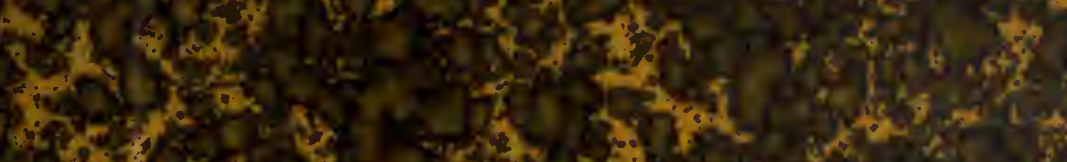
(2)

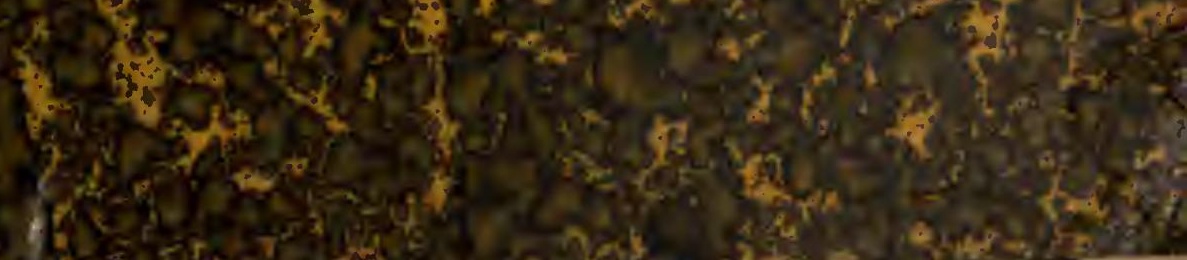


$\left(x^{3}+x^{2}+x^{2}=\right.$

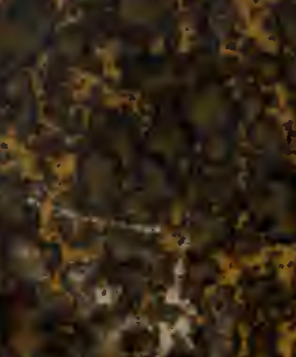

sing

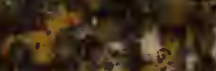
$\lim _{i} \operatorname{lin}^{2}$

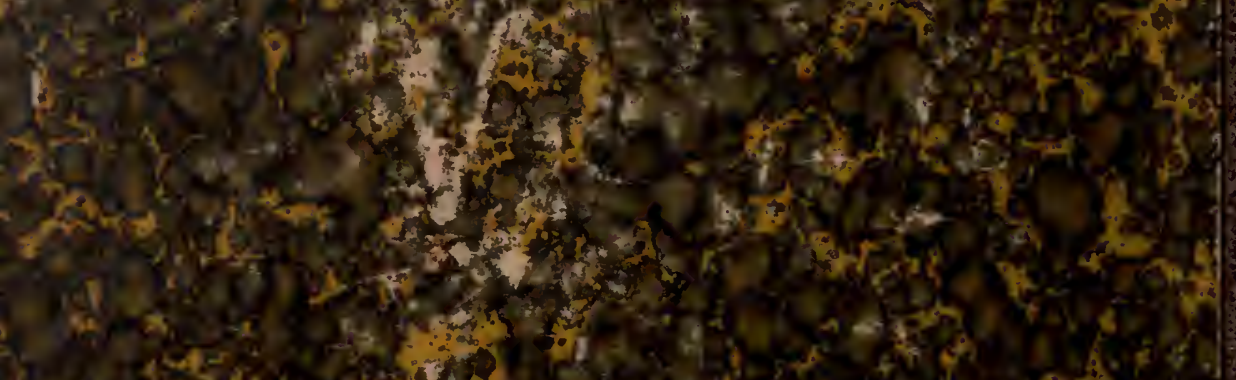

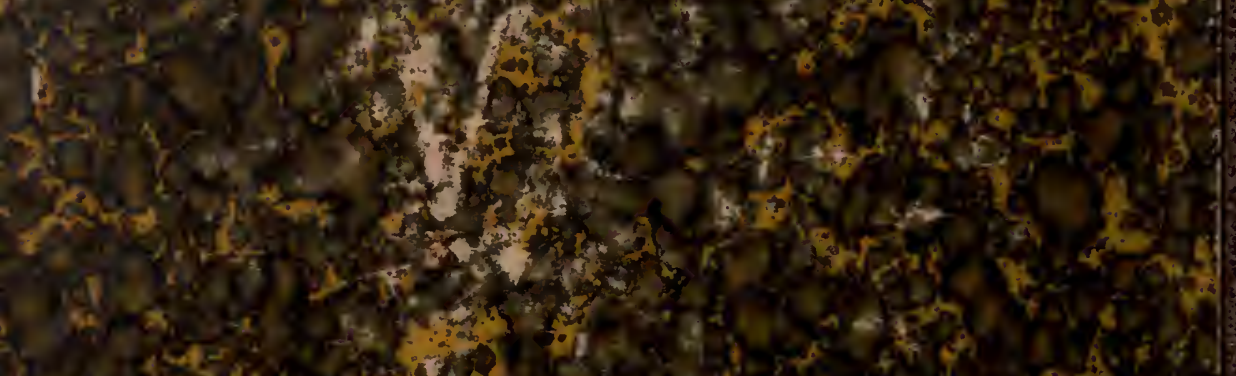

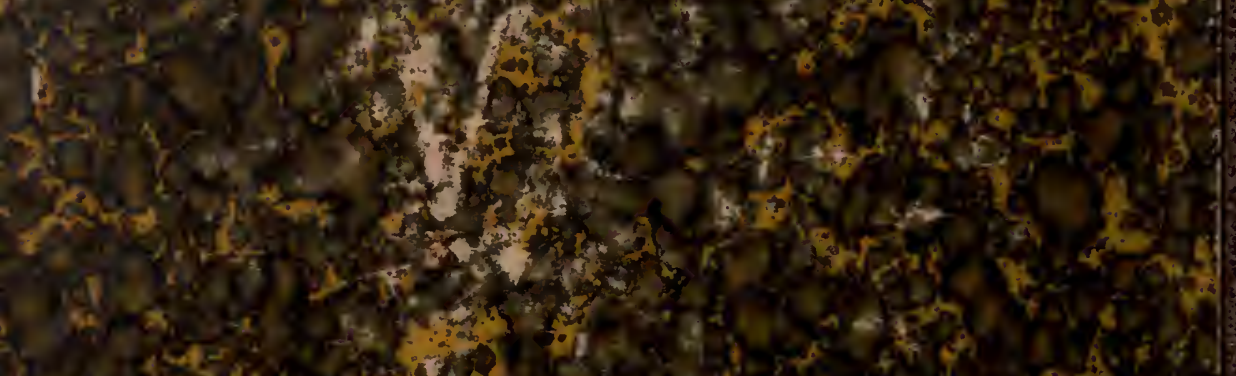

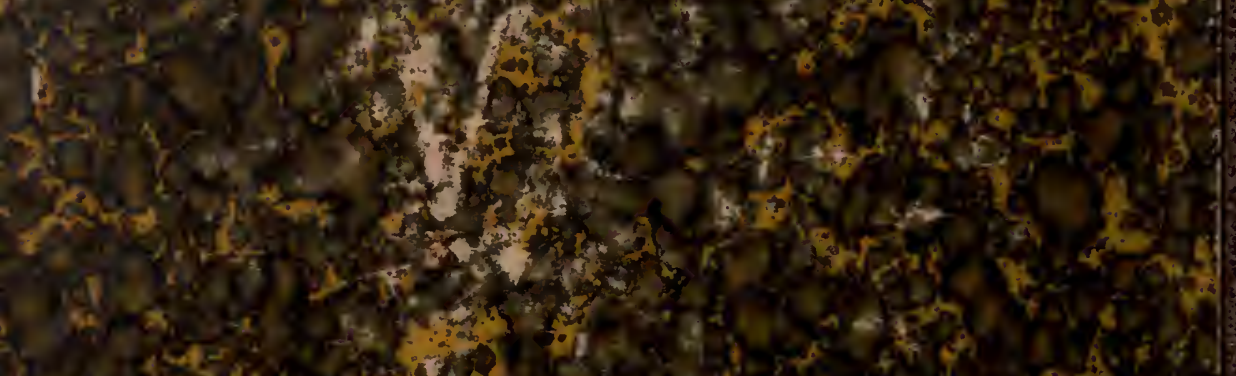

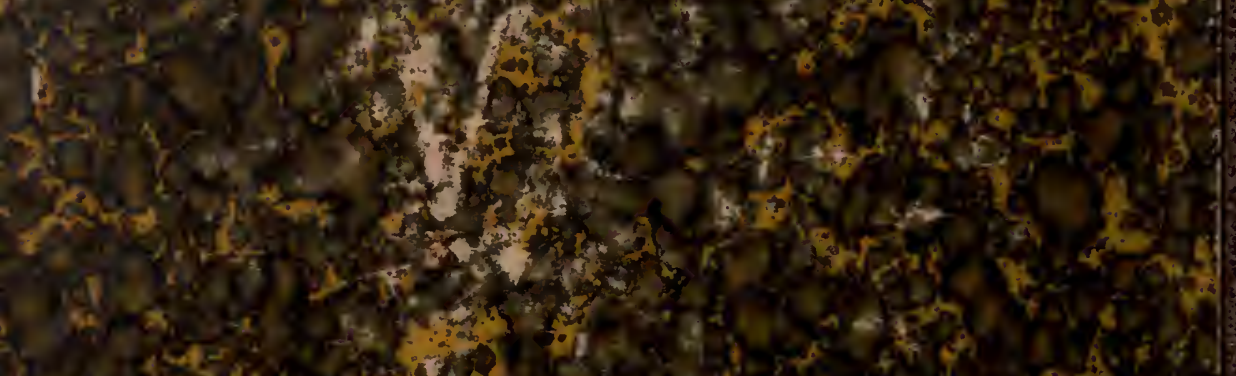

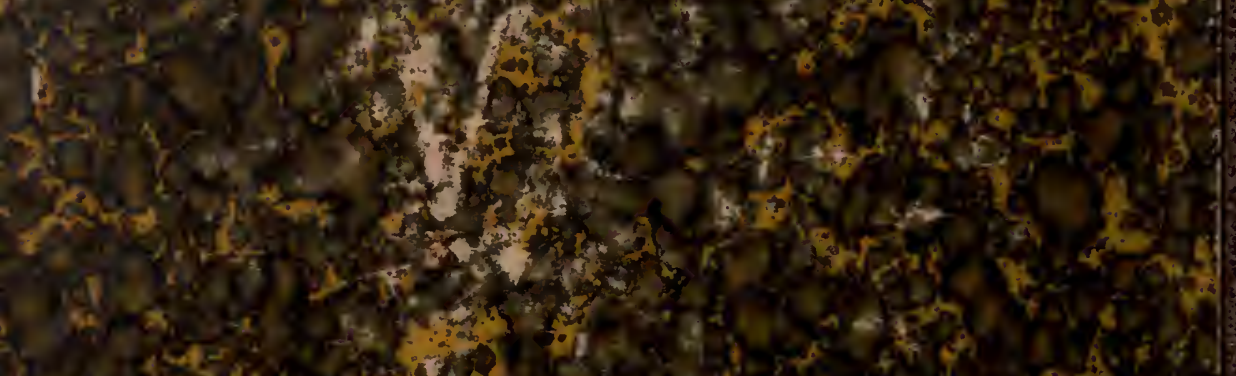
590.5FI $\quad 0001$ FIELDIANA, 200LOGYSCHGO 71905

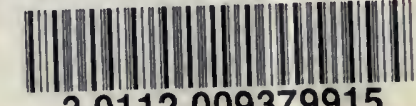
30112009379915

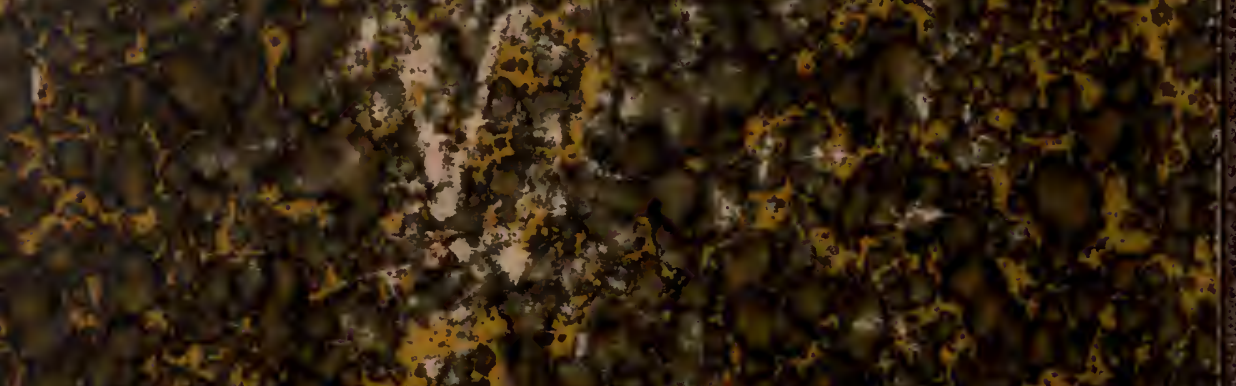
(90)

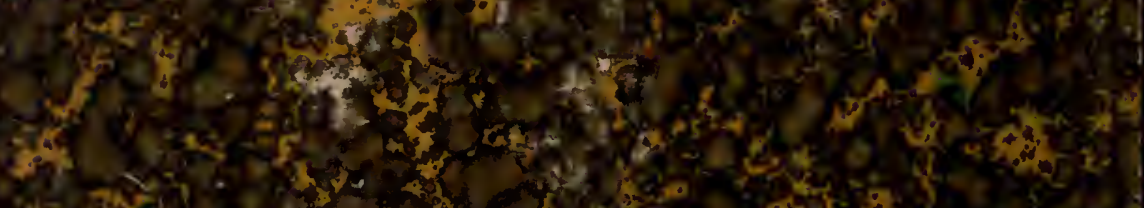
5. 5.50 tren

$$
\text { * }
$$

tis:

(1) - 10,15 (n)

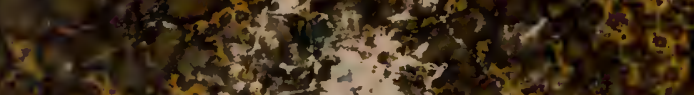

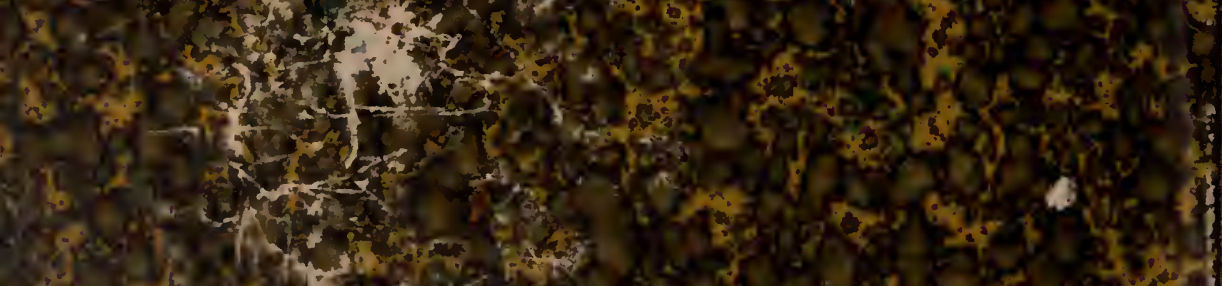
$\lim _{3}$ (1)

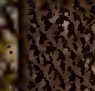

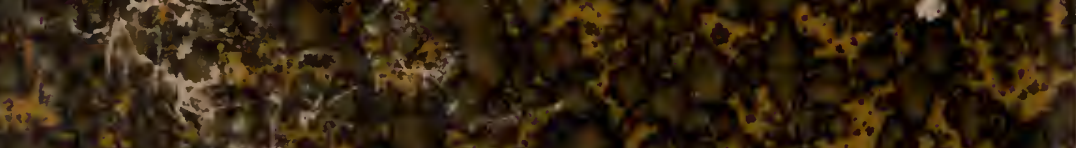

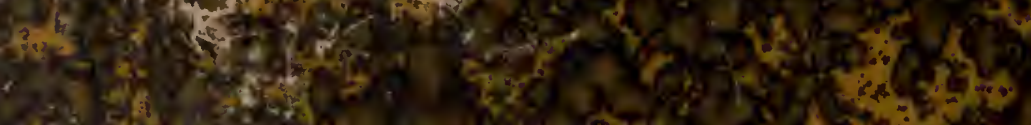

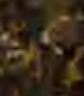

